\title{
BRPKM
}

Buletin Riset Psikologi dan Kesehatan Mental

http://e-journal.unair.ac.id/index.php/BRPKM

e-ISSN: 2776-1851

ARTIKEL PENELITIAN

\section{Hubungan antara Self-Efficacy dengan Kesiapan Kerja pada Mahasiswa Semester Akhir}

\author{
RESIA ANUGRAH WIJIKAPINDHO \& CHOLICHUL HADI* \\ Fakultas Psikologi Universitas Airlangga
}

\begin{abstract}
ABSTRAK
Penelitian ini memiliki tujuan untuk melihat aspek self-efficacy terhadap kesiapan kerja pada mahasiswa semester akhir. Partisipan pada penelitian ini adalah mahasiswa semester akhir di Universitas Airlangga. Pengumpulan data dilakukan dengan metode survei dan menggunakan alat ukur Skala General Self-Efficacy Scale (GSE) dan Skala Kesiapan Kerja. Analisis data yang digunakan adalah uji regresi linier sederhana dan menggunakan program IBM SPSS Statistic 22. Hasil membuktikan selfefficacy berhubungan secara signifikan terhadap kesiapan kerja mahasiswa dengan $\mathrm{p}<0,05$. Selain itu juga didapati self-efficacy mampu memprediksi $R^{2}=0.041$ terhadap kesiapan kerja.
\end{abstract}

Kata kunci: kesiapan kerja, mahasiswa semester akhir, self-efficacy

\section{ABSTRACT}

This research has a goal to look at aspects of self-efficacy on work readiness in final semester students. The participants in this study were final semester students at Universitas Airlangga. Data was collected using a survey method and using the General Self Efficacy Scale (GSE) and Work Readiness Scale as measuring instruments. Analysis of the data used is a simple linear regression test and using the IBM SPSS Statistics 22 program. The results prove that self-efficacy is significantly related to student work readiness with $\mathrm{p}<0.05$. In addition, it was also found that self-efficacy was able to predict $\mathrm{R}^{2}=0.041$ on work readiness.

Keywords: final semester student, self efficacy, work readiness

Buletin Penelitian Psikologi dan Kesehatan Mental (BRPKM), 2021, Vol. 1(2), 1313-1318

*Alamat korespondensi: Fakultas Psikologi Universitas Airlangga, Kampus B Universitas Airlangga Jalan Airlangga 4-6 Surabaya 60286. Surel: cholichul.hadi@psikologi.unair.ac.id

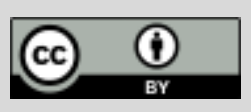

Naskah ini merupakan naskah dengan akses terbuka dibawah ketentuan the Creative Common Attribution License (CC-BY-4.0) (http://creativecommons.org/licenses/by/4.0), sehingga penggunaan, distribusi, reproduksi dalam media apapun atas artikel ini tidak dibatasi, selama sumber aslinya disitir dengan baik. 


\section{P E N D A H U L U A N}

Mahasiswa merupakan suatu kelompok masyarakat yang memiliki status sebagai calon angkatan kerja karena ikatan dengan perguruan tinggi (Baiti dkk., 2017). Lulusan sarjana dari perguruan tinggi bertambah meningkat setiap tahunnya. Ini ditunjukkan dengan banyaknya lulusan yang masih belum memiliki kompetensi yang sesuai standar terutama dalam hal bekerja, sehingga ini menjadi salah satu penyebab mengapa tingginya angka pengangguran di Indonesia (Agustin, 2018).

Hasil dari Badan Pusat Statistik, menunjukkan bahwa grafik angka tidak bekerja pada tingkat sarjana dari tahun 2018 hingga 2021 mengalami kenaikan. Pada tahun 2018 lulusan sarjana yang menganggur 740.370 jiwa per Agustus 2018, dan pada tahun 2021 menunjukkan bahwa lulusan sarjana yang menganggur sebanyak 999.543 jiwa per Februari 2021 (Badan Pusat Statistik, 2021).

Universitas Airlangga sebagai salah satu perguruan tinggi di Indonesia juga ikut menyumbang angka pengangguran lulusan sarjana. Berdasarkan data tracer study pada tahun 2018, 2019, 2020 lulusan Universitas Airlangga rata-rata mendapatkan pekerjaan diatas 4 (empat) bulan. Hal ini dapat dikatakan bahwa lulusan sarjana Universitas Airlangga tidak mudah diterima di dunia kerja atau menunggu mendapatkan pekerjaan (menganggur) selama 4 (empat) bulan pertama. Pada data TS (tracer study) Universitas Airlangga belum sepenuhnya menggambarkan populasi dari lulusan baru Universitas Airlangga, dikarenakan masih banyak lulusan baru yang tidak mengisi tracer study yang sudah diberikan sehingga tidak dapat mencapai target yang sudah ditentukan. Maka lulusan sarjana Universitas Airlangga dapat dikatakan banyak yang masih belum mendapatkan pekerjaan.

Kompetensi atau keahlian yang dimiliki lulusan perguruan tinggi tidak memenuhi standar kebutuhan di dunia, menyebabkan banyaknya perusahaan yang tidak memberikan kesempatan kerja (Wibowo \& Suroso, 2016). Padahal lulusan sarjana yang memiliki kesiapan kerja yaitu keahlian kerja dengan intelektual yang tinggi akan dipertimbangkan oleh perusahaan (Agustin, 2018). Mahasiswa semester akhir sebagai calon lulusan perguruan tinggi perlu agar meningkatkan hard skill dan mengembangkan soft skill nya agar dapat memiliki kompetensi yang baik dan sesuai dengan kriteria yang diinginkan perusahaan (Pool \& Sewell, 2007). Caballero (2010) mengatakan bahwa beberapa perusahaan memberikan ekspektasi yang tinggi pada lulusan sarjana yang ingin bekerja, dikarenakan individu dengan kesiapan kerja yang tinggi akan berpotensi dalam kemajuan karirnya. Dalam mendapatkan pekerjaan, calon lulusan sarjana diharapkan dapat memiliki kesiapan kerja yang tinggi dengan menguasai kemampuan akademik maupun non akademiknya, karena akan menjadi poin penting terkait kompetensi yang dimiliki dengan standar kompetensi dalam dunia kerja (Agustin, 2018).

Kesiapan kerja merupakan pengetahuan, keterampilan, serta attitude yang dimiliki individu sehingga dapat membantu dalam hal berkontribusi terhadap pencapaian tujuan organisasi tempat individu bekerja Makki dkk. (2005 dalam Agustin, 2018). Winkel \& Sri Hastuti (2005) mengatakan bahwa terdapat sejumlah penyebab yang mempengaruhi kesiapan kerja yaitu kepintaran suatu individu dalam mencapai organisasi, kepribadian, skill, motivation, health, dan cita-cita. Kepribadian menjadi penyebab utama dalam mempengaruhi kesiapan kerja. Seseorang dengan kepribadian yang baik serta memiliki high integrity, kemungkinan individu tersebut tidak mengalami kesulitan maupun hambatan ketika dihadapkan suatu masalah dan mampu beradaptasi dengan lingkungan baru, yaitu dunia pekerjaan.

Self-efficacy menjadi komponen utama dari kepribadian seseorang untuk melakukan sesuatu tujuan yang telah dikehendaki, khususnya yang berkaitan dengan kesiapan kerja. Utami (2013) berpendapat bahwa lulusan perguruan tinggi diharapkan mampu terjun dalam dunia kerja dengan high self-efficacy. 
Self efficacy merupakan keyakinan akan kemampuan yang dimiliki seseorang terkait pengorganisasian dalam merespon tujuan yang telah dikehendaki (Bandura, 1997).

Robbins \& Judge (2007) individu dengan self-efficacy tinggi ditandai dengan dapat mengatasi masalah secara efektif, dapat mencapai target yang sudah ditentukan, serta yakin berhasil dan sukses dengan kemampuannya dalam menghadapi hal-hal yang sulit. Apabila self-efficacy individu itu rendah akan mengalami kebingungan untuk mengatasinya serta cenderung putus asa, ketika individu dapat mengatasi suatu permasalahan yang sulit terutama dalam hal bekerja serta mampu secara efektif mengatasi masalah tersebut maka individu memiliki self-efficacy yang baik. Oleh sebab itu, dalam dunia bekerja self-efficacy dibutuhkan agar mampu mengatasi permasalahan di dunia kerja (Wibowo \& Suroso, 2016).

Berdasarkan pemaparan diatas, peneliti tertarik untuk meneliti apakah ada korelasi antara self-efficacy dengan kesiapan kerja pada mahasiswa semester akhir di Universitas Airlangga. Penelitian ini memiliki tujuan untuk mengetahui ada tidaknya korelasi antara self-efficacy dengan kesiapan kerja pada mahasiswa semester akhir di Universitas Airlangga. Selain itu, penelitian ini juga bertujuan untuk mencari seberapa besar self-efficacy mampu memprediksikan tingkat kesiapan kerja pada mahasiswa akhir di Universitas Airlangga.

\section{Desain Penelitian}

\section{E T O D E}

Peneliti menggunakan pendekatan kuantitatif, yaitu untuk menguji kebenaran teori yang diangkat dan dianalisis secara sistematis serta mudah untuk dikomunikasikan (Neuman, 2014). Pengumpulan data menggunakan metode survei. Teknik analisis data yang digunakan dalam penelitian ini menggunakan simple linear regression dengan bantuan software IBM SPSS Statistic 22 for Windows.

\section{Partisipan}

Partisipan pada penelitian ini yaitu mahasiswa semester akhir di Universitas Airlangga. Teknik pengambilan sampel menggunakan nonprobability sampling yaitu accidental sampling. Accidental sampling merupakan cara pengambilan dengan menggunakan sampel saja yang muncul dan sesuai kriteria yang sudah ditentukan. Peneliti menggunakan rumus dari perspektif Tabachnick dan Fidell untuk menentukan jumlah sampel minimal yaitu 58 partisipan. Jumlah keseluruhan partisipan pada penelitian ini sebanyak 111 partisipan $\left(M_{\text {usia }}=21,5 ; S D_{\text {usia }}=0,658 ; 77,48\right.$ persen perempuan) yang merupakan mahasiswa semester akhir di Universitas Airlangga.

\section{Pengukuran}

Pada variabel self efficacy peneliti menggunakan skala yaitu General Self Efficacy Scale (GSE) dan sudah diterjemahkan ke dalam 32 bahasa termasuk bahasa Indonesia yang disusun oleh Matthias Jerusalem dan Ralf Schwarzer. Skala ini terdapat 10 aitem dengan 4 pilihan jawaban (1="sangat tidak sesuai", $2=$ "tidak sesuai", 3="sesuai", 4="sangat sesuai"), koefisien $(\alpha=, 78-, 91)$. Sedangkan untuk mengukur variabel kesiapan kerja menggunakan skala yang disusun oleh Kusumaputri (2018) berdasarkan aspekaspek kesiapan kerja yang dikembangkan Brady (2010). Skala ini terdiri dari 48 aitem dengan 5 pilihan jawaban (1="sangat tidak setuju", 2="tidak setuju", 3="ragu-ragu", 4="setuju", 5="sangat setuju"), dengan koefisien $(\alpha=, 72)$. 


\section{Analisis Data}

Penelitian ini menggunakan uji regresi linear sederhana. Sebelum dilakukan uji regresi sederhana, dilakukan uji asumsi seperti uji normalitas, uji linearitas, dan uji homokedastisitas. Analisis tersebut dilakukan dengan menggunakan perangkat lunak IBM SPSS Statistic 22 for Windows.

\section{HAS IL PEN EL I T I A N}

\section{Analisis Deskriptif}

Hasil dari analisis deskriptif statistik pada 111 partisipan $(N=111)$ menunjukkan nilai terendah $(M i n)$ pada variabel self efficacy sebesar 14 dan nilai tertinggi (Max) sebesar 39, dengan rata-rata (Mean) sebesar 28,41 dan simpangan baku (SD) sebesar 4,963. Pada variabel kesiapan kerja menunjukkan nilai terendah (Min) sebesar 132 dan nilai tertinggi (Max) sebesar 202, dengan rata-rata (Mean) sebesar 158,03 dan simpangan baku (SD) sebesar 10,519. Partisipan pada penelitian ini mendominasi kesiapan kerja dengan kategorisasi sedang sebesar 87 partisipan (78,4\%), kategorisasi tinggi sebesar 13 partisipan $(11,7 \%)$, dan kategorisassi rendah sebesar 11 partisipan $(9,9 \%)$.

\section{Uji Regresi Linear Sederhana}

Hasil dari uji regresi linear sederhana, diketahui $\left(\mathrm{F}[1,109]=4.627 ; \mathrm{p}<0.05 ; R^{2}=0.041\right)$. Nilai ini menunjukkan tingkat self efficacy pada penelitian ini mampu memprediksikan kesiapan kerja sebesar 4.1\%. Variabel self efficacy menghasilkan $(B=0,428 ; 95 \%$ CI $[0,034 ; 0,822] ; S E=0,199 ; t=2,151 ; p<0,05)$ yang menunjukkan nilai positif, apabila tingkat self efficacy yang dimiliki individu meningkat akan diikuti dengan kesiapan kerja yang tinggi, sedangkan individu dengan self efficacy rendah akan berdampak pada penurunan pada kesiapan kerja individu tersebut.

\section{I S K U S I}

Berdasarkan hasil analisis data, diketahui bahwa hipotesis pada penelitian ini diterima, yaitu ada korelasi antara self efficacy dengan kesiapan kerja. Penelitian ini memperoleh persamaan regresi $\mathrm{Y=}$ $145,873+0,428 X$, artinya setiap penambahan $1 \%$ tingkat self efficacy, makan kesiapan kerja akan meningkat sebesar 0,428 . Nilai koefisien regresi yang didapat sebesar $\left(R^{2}=0.041\right)$, artinya self efficacy mampu memprediksi kesiapan kerja sebesar 4,1\% dan sisanya diprediksi oleh variabel lain yang tidak diteliti.

Hasil penelitian ini sejalan dengan penelitian yang dilakukan oleh Kusumaputri (2018), hasil penelitiannya menemukan bahwasanya terdapat hubungan yang positif antara kepercayaan diri dengan kesiapan kerja, dengan hasil korelasi sebesar $r=0,746$ dan sumbangan efektif 55,6\%. Kemudian penelitian dari Adelina (2018) menunjukkan bahwa antara self efficacu dengan kesiapan kerja terdapat hubungan yang positif, serta penelitian dari Baiti dkk. (2017) menunjukkan bahwa career self-efficacy dengan kesiapan kerja pada mahasiswa semester akhir terdapat hubungan yang positif. Yuwanto, dkk. (2016) juga meneliti tentang self-efficacy dan kesiapan kerja, hasilnya mengatakan bahwa terdapat hubungan yang positif dan signifikan antar kedua variabel.

Self-efficacy merupakan salah satu anteseden dari kesiapan kerja. Menurut Bandura (1997) self-efficacy merupakan keyakinan akan kemampuan yang dimiliki individu untuk mengorganisasikan dan melakukan suatu tindakan dalam memenuhi kebutuhannya. Individu dengan high self efficacy dapat 
memahami skills dalam menandingi dunia kerja dengan integritas yang dimilikinya, serta dapat mengatasi suatu masalah secara efektif dan yakin akan meraih kesuksesan, namun sebaliknya individu dengan self-efficacy rendah cenderung mudah menyerah, tidak dapat menyelesaikan masalah secara efektif karena tidak yakin dengan kemampuan yang dimilikinya (Robbins \& Judge, 2007). Wiharja dkk. (2020) mengatakan pada penelitiannya bahwa aspek-aspek self efficacy mampu secara simultan meningkatkan mahasiswa untuk memasuki dunia kerja.

\section{S I M P U L A N}

Kesimpulannya adalah terdapat hubungan yang signifikan dan positif antara variabel self-efficacy dengan variabel kesiapan kerja. Hubungan antara self-efficacy dengan kesiapan kerja ini bersifat positif, artinya meningkatnya self-efficacy pada individu dapat berdampak pada kesiapan individu tersebut dalam memasuki dunia kerja.

Saran untuk peneliti selanjutnya yaitu untuk memperluas populasi dan jumlah sampel agar hasil penelitian menjadi lebih baik lagi. Selain itu, peneliti selanjutnya juga harus mempertimbangkan variabel atau aspek lainnya yang mampu mempengaruhi kesiapan kerja pada mahasiswa seperti kesadaran, perencanan karir, soft skill, dan experience. Peneliti selanjutnya juga disarankan untuk menambah data demografis untuk membantu analisis pada penelitian.

\section{U C A P A N T ER I MAKASIH}

Puji syukur kepada Allah SWT, atas rahmat dan serta hidayahNya, peneliti dapat menyelesaikan penelitian ini. Terima kasih kepada keluarga, saudara, teman, dan pihak lainnya yang telah mendukung peneliti selama proses penelitian ini. Serta terima kasih kepada peneliti sebelumnya yang telah memberikan izin untuk menggunakan alat ukur kesiapan kerja.

\section{DEKLARAS I POTENSI TERJADINYA KONFLIK KEPENTINGAN}

Resia Anugrah Wijikapindho dan Cholicul Hadi tidak bekerja, menjadi konsultan, memiliki saham, atau menerima dana dari perusahaan atau organisasi manapun yang mungkin akan mengambil untung dari diterbitkannya naskah ini.

\section{PUSTAKA ACUAN}

Adelina, D. (2018). Hubungan Antara Self Efficacy Dengan Kesiapan Kerja Pada Mahasiswa Tingkat Akhir (Undergraduate thesis, University of Muhammadiyah Malang).

Agustin, B. (2018). Pengaruh Self Efficacy Terhadap Kesiapan Kerja Pada Mahasiswa Semester Akhir di Universitas Muhammadiyah Gresik (Undergraduate thesis, Universitas Muhammadiyah Gresik).

Badan Pusat Statistik. (2021). Pengangguran Terbuka Menurut Pendidikan Tertinggi yang Ditamatkan 1986-2021. Melalui https://www.bps.go.id/statictable/2009/04/16/972/pengangguranterbuka-menurut-pendidikan-tertinggi-yang-ditamatkan-1986---2017.html [21/7/21]

Baiti, R. D., Abdullah, S. M., \& Rochwidowati, N. S. (2017). Career Self-Efficacy dan Kesiapan Kerja Pada Mahasiswa Semester Akhir. Jurnal Psikologi Integratif, 5(2), 128-141. http://ejournal.uin-

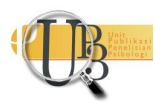


suka.ac.id/isoshum/PI/article/view/1411/1212

Bandura, A. (1997). Theoretical Perspectives: the nature of human agency. Self-efficacy: The exercise of control, 3.

Brady, R. P. (2010). Work readiness inventory: Administrator's guide. Journal of International, 5(1), 141160.

Caballero, C. L. (2010). Work readiness in graduate recruitment and selection: a review of current assessment methods, Journal of teaching and learning for graduate Work readiness in graduate recruitment and selection: A review of current assessment methods. 1(1), 13-25. http://hdl.handle.net/10536/DRO/DU:30030444

Kusumaputri, R. Y. (2018). HUBUNGAN ANTARA KEPERCAYAAN DIRI DENGAN KESIAPAN KERJA PADA SISWA SEKOLAH MENENGAH KEJURUAN (SMK). (Undergraduate thesis, Universitas Islam Indonesia).

Neuman, W. L. (2014). Social research methods: Qualitative and quantitative approaches: Pearson new international edition. Pearson Education Limited.

Pool, L. D., \& Sewell, P. (2007). The key to employability: Developing a practical model of graduate employability. Education and Training, 49(4), 277-289. https://doi.org/10.1108/00400910710754435

Robbins, S. P., \& Judge, T. A. (2007). Organizational Behavior. Pearson Education.

Utami, Y. G. D. (2013). Self efficacy dengan kesiapan kerja siswa sekolah menengah kejuruan. Jurnal Ilmiah Psikologi Terapan, 1(1), 40-52.

Wibowo, A., \& Suroso. (2016). Adversity Quetient, Self Efficacy dan Kesiapan kerja Siswa Kelas XII Program Keahlian Multimedia SMKN 1 Kabupaten Jombang. Persona:Jurnal Psikologi Indonesia, 5(02), 174-180. https://doi.org/10.30996/persona.v5i02.735

Wiharja, H., Rahayu, S., \& Rahmiyati, E. (2020). PENGARUH SELF EFFICACY TERHADAP KESIAPAN KERJA MAHASISWA PENDIDIKAN VOKASI. VOCATECH: Vocational Education and Technology Journal, 2(2), 11-18.

Winkel, W. S., \& Hastuti, M. S. (2005). Bimbingan dan konseling di institusi pendidikan. Media Abadi.

Yuwanto, D., Mayangsari, M. D., \& Anward, H. H. (2016). Hubungan Efikasi Diri Dengan Kesiapan Kerja Pada Mahasiswa Yang Sedang Mempersiapkan Skripsi. Jurnal Ecopsy, 1(4). https://doi.org/10.20527/ecopsy.v1i4.506 